\title{
Switching factor products: nurses' experience with NovoEight
}

Debra Pollard, Kate Khair, Mike Holland

Haemophilia nurses in the UK are instrumental in supporting people with haemophilia in selfmanagement, including managing treatment options, recording treatment use and understanding the budgetary impact of prescribing practice. The widespread use of prophylaxis identified haemophilia as a high cost disorder to treat, resulting in a financially successful national tendering process with increased scrutiny of clotting factor use at both individual and haemophilia treatment centre level. The UK tenders, undertaken at a national level every three years, have ensured access to current and new therapies at the most cost-effective price through economies of scale in committing to purchase large volumes from suppliers.

In the 2018 tendering round, NovoEight ${ }^{\circledR}$ (NovoNordisk) was added to the prescribing list and other recombinant factors were withdrawn, resulting in changes in prescribing for individual people with haemophilia. This 'switching' process is not uncommon in the UK, where national tenders have been in place since 2004. However, the unseen additional workload for nurses, driven by the demands of timely switching to meet product volumes and contracts, has never been

DEBRA POLLARD

Katharine Dormandy Haemophilia \& Thrombosis Centre,

Royal Free Hospital, London, UK.

Email: Debra.Pollardanhs.net

KATE KHAIR

Haemnet, London, UK

MIKE HOLLAND

Haemnet, London, UK

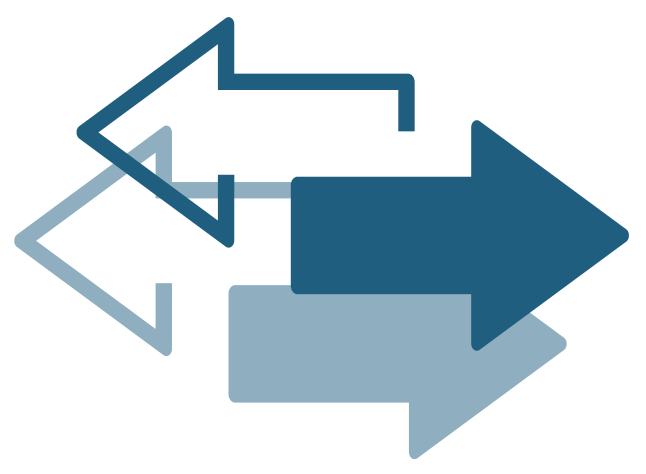

Focusing on the introduction of NovoEight, a survey of haemophilia nurse specialists on their experience of managing factor product switches reveals the hidden workload involved

captured. During the 2018 switch we interviewed 11 nurses and one operational manager from haemophilia centres across the UK to identify the barriers and facilitators to instigating this change.

Ultimately the switching was completed in a timely manner, demonstrating significant cost reductions for factor concentrates. The unseen workload of the nurse - identifying which patients should have their product switched, discussion with and education of patients/ families, adjusting prescriptions for home delivery of clotting factor concentrates and stock management and control to avoid waste, and organising the necessary additional clinic visits - was identified and costed based on salary per hour. Nurses remained positive that they were able to undertake this additional role but recognised that, with no specific national guidance regarding product choice, there may have inevitably been differences in approach between treatment centres.

This is an Open Access article distributed under the terms of the Creative Commons Attribution-NonCommercial-NoDerivs License (https://creativecommons.org/licenses/by-nc-nd/3.0/) which permits use and distribution in any medium, provided the original work is properly cited, the use is non-commercial, and no modifications or adaptations are made. Copyright is retained by the authors. 
Keywords: Nurse experience, switching treatment, haemophilia, NovoEight

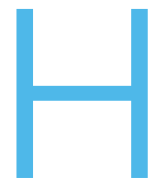

aemophilia is characterised by a deficiency

of coagulation factor VIII or IX in haemophilia

$A$ and $B$ respectively. In the $U K$, following

the introduction of a national policy ${ }^{[1]}$, most

people with haemophilia are treated with replacement

clotting factor concentrates produced by recombinant technologies. The widespread adoption of factor VIII and IX prophylaxis and increasing usage over recent decades has led to haemophilia being considered an expensive condition to treat ${ }^{[2]}$. This has resulted in increasing levels of administrative scrutiny from payers and attempts to procure clotting factor concentrates more efficiently and collectively. Since 2004, there has been a national tender system for the purchasing of clotting factor concentrates managed by the Commercial Medicines Unit, a part of NHS England. Over time, this has led to significant savings in the National Health Service (NHS) budget ${ }^{[3]}$.

The tendering process for factor concentrates now operates through a system whereby companies bid for volumes of the market every three years. Following each new contract, haemophilia centres must commit to using certain volumes of particular products. Consequently, some patients have to switch product in a timeframe that allows the target volumes to be reached within a year of contract award.

Tender-mandated factor switches are associated with an additional workload that involves:

- Ensuring product is stocked by hospitals

- Liaising with data managers

- Identifying and informing patients

- Updating patient prescriptions for both in-hospital usage and home delivery of clotting factor concentrates

- Liaising with home delivery companies around stock management and to limit product wastage

- Managing pharmacokinetic assessments and inhibitor screens, if required

- Counselling and educating patients and families.

Inevitably, much of the work of managing the process of switching products falls to specialist haemophilia nurses ${ }^{[4]}$. However, there has been little in the way of formal assessment of the additional workload that tender-mandated factor switches impose on haemophilia nurses, or the hidden cost that this incurs. The recent (spring 2018) introduction of turoctocog alfa (NovoEight ${ }^{\oplus ;}$ Novo Nordisk), and the loss of other regularly used products, offered the opportunity to gain valuable insights into the role of the specialist haemophilia nurse in switching factor products on a relatively large scale.

\section{METHODS}

In advance of the 2018 tender-mandated switch, a roundtable discussion meeting of experienced haemophilia nurse specialists was held focusing on the management of product switches in light of the pending national recombinant factor VIII tender. This was organised and funded by Novo Nordisk, although the discussions and output were not product-specific. Following that meeting, the participants developed a practical guide primarily for new nursing staff who had not previously experienced a significant product switch (Table 1). This, together with sample templates of a checklist and a patient letter, were shared with nurses via the Haemnet website (www.haemnet.com).

Subsequently, we undertook a series of semistructured telephone interviews with 12 senior representatives from haemophilia centres across the UK. Interviews focused on the experience of managing product switches following the recent national recombinant factor VIII tender, with a particular focus on the introduction of NovoEight as this was new to the UK market. All interviews were conducted in July/ August 2018. Healthcare provider research in the UK does not require ethical approval, however verbal consent was taken from participants.

\section{RESULTS}

Interviews were conducted with 11 senior haemophilia nurses and one operational services manager from haemophilia centres across the UK. Collectively, participants claimed experience of switching products for approximately 190 people with haemophilia to NovoEight (Table 2). Three of the nurses were from paediatric-only centres. While all nurses had experienced the occasional need to change a patient's product for clinical reasons, for most nurses, this was their third experience of a mass tender-mandated factor switch; two had experienced just two previous contract switches.

\section{Patient targeting}

When asked who decided which patients should switch product, most said it was a multidisciplinary team decision or one made by the doctor and a nurse; two nurses said it was a nurse-only decision (albeit with approval of the centre doctor) and in one case it was a doctor-only decision (Table 2). 
Most patients were told that they would switch product at a routine clinic visit; specific letters or phone calls were only made if the patient was not due for a routine clinic review during the time period in which the switch had to be made.

"We sent ... a letter to all of our patients, saying that a tender process had gone on and that there would be a change in some of their treatments, depending on what they were currently on. And then, when those patients came in for their followups, we just grabbed them at that point, rather than bring them in for an extra clinic." [HNS12]

"Patients were written to and the tender process explained when we were looking to switch them." [HNS7]

"Everyone on home treatment got a letter to say that this is happening and they may well be changed." [HNS6]

Patients themselves appeared to be relatively uninvolved in the decision; they were not consulted.

"I don't think they were as involved this time as they have been in the past. But I still think that we have to put them at the centre of the process, i.e. the letters, the communication, there were phone calls. There was the opportunity to decline, which I do feel is important." [HNS7]

By far the most common reason for not switching a patient's product was a previous history of an inhibitor (mentioned by $75 \%$ of nurses). Difficulties in regard to communication (e.g. learning or language difficulties) were also cited by several nurses.

There was no official guidance from the UK Haemophilia Centre Doctors' Organisation (UKHCDO) with regard to which patients should have their product switched. Unlike the earlier introduction of extended half-life products, this switch required no pharmacokinetic monitoring ${ }^{[5]}$, and was seen as a relatively straightforward 'like-for-like' factor VIII switch. When asked about the criteria used in the decision-making process, decisions appeared to have been based on the imperative to meet volume targets, resulting in two principal target groups:
- Patients on products due to be withdrawn from the UK market

"All of the patients who were on Kogenate ${ }^{\circledR}$ and Helixate ${ }^{\circledR}$ had to switch, and they were told, 'You have to switch and this is the product we'd like you to go on, '... and we didn't have any arguments from anybody." [HNS3]

- High volume users

"By and large, I think we try and move the highest users so you're moving less people ... Is that the right way? It's not scientific at all ..." [HNS9]

Within this, however, some specific considerations could be identified. For instance, one paediatric nurse saw the switch as an opportunity to reduce infusion volumes in one patient, or for those thought to be not responding to their current treatment. One centre specifically targeted NovoEight to new mild and moderate patients. But all nurses tended to consider the nature of the individual patient and whether they would cope well with a switch. This also included thinking about the needs of carers:

\section{"We did siblings too - I wouldn't have switched one and not the other ... the mother wouldn't have coped." [HNS10]}

Most nurses admitted they would not consider those patients they thought were unlikely to agree to switching, or those in whom a product switch might provoke anxiety. As a result, only three nurses said patients had refused to switch to the new product. In five patients, this was due to the fear of an inhibitor, while the sixth was a patient new to prophylaxis who was unwilling to make a further change so soon.

\section{Workload}

For nurses, the additional workload involved in a tender-mandated product switch begins very early.

"Obviously, we had to inform the Trust that there was a new drug for the formulary as well; so, pharmacy need notifying of a new product for it going through ... if they need it prescribing in hospital. And also finance and all those other teams need to know as well, because you're changing a product and costings." [HNS3] 
There is a considerable effort involved in ensuring a new named product is on the hospital drugs and therapeutics prescribing formulary, and this can add to the difficulty of achieving switches in a timely way and meeting target volumes. All nurses agreed that tender-mandated switching resulted in a significant extra workload, principally for the nurse and data management teams. However, attempts to quantify this additional workload were difficult: most nurses felt the workload was simply absorbed (Table 3).

For those who were independent prescribers, the workload was probably greater, but easier in the sense of not having to liaise with others who may not always be available. In the main, the present switch did not require centres to change home delivery companies, but where it did this would have added significantly to the workload due to additional paperwork.

\section{"If you were having to change home delivery} company, that makes a big difference because of all the registration forms and things like that. But you absorb it." [HNS2p]

One practical challenge is ensuring that the patient uses all of his old product before the switch. All of the nurses advised their patients either by letter, phone or in person (where this coincided with a routine visit) to use up all of their old product, but responsibility for this was primarily down to the patients. For some nurses this meant rescheduling appointments.

"The biggest obstacle for me, which took a lot of time, was them being able to use their product that they had. I had to liaise with families to time their appointment with the clinic appointment, which means you have to change things a little bit." [HNS1p]

"Trusting them. You can see on Haemtrack what they've been up to. We ran them down just, you know, a couple of days before we sent the new product. You can't leave them without product in case they have a bleed. But, no, there was nothing wasted." [HNS10]

"The patients were instructed in the letter to use up all their old product before the switch. I do know that some centres are very, very good at chasing every minute detail, but we just have too big a number to do it." [HNS4]
"We did ask the patients to let us know how much they'd got at home. Most of them are coming in for their follow-ups at six months anyway, so they're generally running out of their prescription at that point. So, it was just an easier way of ensuring that they had very little left and we just changed them over at that point and said, 'Use all of your old product up, and then use your new product when you get it."' [HNS12]

With no official UKHCDO guidance about pharmacokinetic or inhibitor testing regarding this particular switch, eight of the 12 participants did not undertake any additional pharmacokinetic assessment, but four did so on at least some patients, usually where these were due as part of a routine visit. Similarly, preand post-switch inhibitor screens were not undertaken outside of the patient's routine six-month visits.

Given the additional impact upon workload, most of the nurses agreed that patients should be switched no more than every three years:

"I wouldn't like to do it regularly, one for the workload and one for the patients."

\section{DISCUSSION}

Haemophilia is an expensive condition to treat. The average adult with severe haemophilia $A$ in the UK used 250,000 IU of factor VIII in 2011/2012, at an annual cost in excess of $£ 100,000^{[3]}$. The cost has led to growing scrutiny over treatment as well as pressure to procure clotting factor concentrates more efficiently. In the UK, clotting factor products are purchased centrally for use within the NHS in a system by which pharmaceutical companies bid for volumes of the market every three years. This has resulted in substantial cost savings at a central level. However, it takes no account of the hidden workload cost of switching patients' treatment from one clotting factor to another or additional blood test costs where these are performed.

The key stages in product switching begin with identifying the patients, followed by:

"Let them know ... Run down their existing stock. Get your new prescriptions. We sent out demo kits. None of them wanted to come in, because a lot of them live far, and they're all used to mixing different products. So, we sent very detailed instructions out, demo kits, followed up that they'd done that, etc. And then we switched the prescription over. Again, we followed up with a phone call." [HNS10] 
In addition, most factor in the UK is now delivered to patients by third-party home delivery companies who operate contracts with specific pharmaceutical companies. This could potentially impact upon the patients likely to be targeted for switching.

For most nurses, however, the additional workload proved very difficult to quantify:

"I think all told it would probably be two to three days' work. You're just doing an hour here and a couple of hours there, so probably three days' work would be what was involved." [HNS12]

"Sometimes a little bit of it is done on one day and then ... or on another day. We tend not to bring too many people in on one day to do it, so we just try and incorporate it into the day-to-day rather than bringing them to a full clinic. You just almost accept that it has to be done." [HNS9]

"It's so hard to quantify a lot of what we do, for that reason - it just becomes part of the day. And other things go to one side, so you fill your day with something else. It might be a bit more than a day, actually, if you think about preparing for it first of all, and then your initial discussion with patients, the letters and the initial discussion. So, more than a day, I'd say." [HNS6]

Based on the $2017 / 18$ pay rate for a Band 7 haemophilia nurse in the UK ( $£ 31,696$ to $£ 41,787$ basic national salary without regional 'uplifts' and additional employer costs), and assuming an additional workload associated with this product switch of one to three days, the nursing cost alone would be in the region of $£ 365$ to $£ 481$ per centre.

That the impetus for product switches is principally financial is recognised by both nurses and patients:

"The issue about cost comes into it, whether we like it or not. Because if something works well and it's just as effective and it's safe and it's slightly cheaper, you have to broach that subject," [HNS1p]

"[Patients do ask] Is this about money? Is this because this is cheaper? And, obviously, you have to answer that honestly and say it's still been proved to be as effective and, 'We wouldn't put you on this if we didn't think it was going to be right for you.' The same kinds of things we'd ask if it was us." [HNS6]
As financial pressure on healthcare services continues, product switches are likely to continue to be a routine aspect of the haemophilia nurse's role. It will be important to ensure that this does not conflict with the nurse's role as principal advocate for the patient. Switching patients' factor products has the potential to cause conflict. In a recent assessment of patients whose treatment was switched to extended half-life factors, we found that for patients, product switches could be disruptive: if not handled and communicated appropriately, switching could affect relationships with health care professionals as well as their confidence in treatment ${ }^{[6]}$. The current study suggests that nurses are, in the main, sensitive to patients' concerns.

"You know your patients, you know their history, you know they've switched before, so you learn ways to manage a good switch." [HNS7]

\section{"We would endeavour not to switch people who have a history of an inhibitor, even though that is not a reason for not switching. We would endeavour to keep members of one family in one household on one product. There may be reasons such as you know the patient well and they have anxiety anyway, and you don't really want to provoke further anxiety by change, which I think is a good reason. I think it's worth commenting that, on this occasion, there has been no problem with introducing the new device." [HNS4]}

The comment relating to the device was echoed by other nurses, who had used the 'opportunity' of the switch to avoid using a product-linked administration device that had proven unpopular with patients and nurses, principally because it involved vial-to-vial transfer. The new product is administered by means of pre-filled diluent syringe (MixPro ${ }^{\circledR}$ ), which has previously been evaluated among patient/carer users and nurses ${ }^{[7]}$. It was described as being user-friendly, simple and quick; its compactness and portability were highlighted as advantages for storage and travel.

Perhaps the major reason for patients refusing to switch products, and for nurses feeling reluctant to switch patients' products, was the fear of the risk of an inhibitor.

"I think we had one patient who'd had a previous inhibitor, had tolerised, so we decided we were just going to keep him on his previous one and not swap him." [HNS12] 
Such fears are based on early studies suggesting that particular products (e.g. recombinant vs. plasmaderived and full length vs. B-domain modified) may be associated with increased risk. However, current evidence does not suggest that switching products significantly influences inhibitor development, although there is a need for regular inhibitor testing ${ }^{[8,9]}$. There is a need for nurse educators to reinforce these messages and for nurse specialists to ensure better understanding among patients and families.

However, the very fact of a tender perhaps results in a limited range of product choices. This poses a conflict with the current NHS agenda around 'choice', as set out in the Department of Health's Choice Framework, first published in April $2016^{[10]}$. This document set out a goal of "significantly improving patient choice by 2020 and in doing so, empowering patients to shape and manage their own health and care." It is, therefore, a concern that:

\section{"No, they weren't really offered a choice of switching. It's almost issued as a fait-accompli. Under changes in tendering processes, we need to do this sort of thing; we need to make switches." [HNS9] \\ "No, they weren't involved, just, 'This is what's happening.' I suppose if somebody had felt very strongly about not changing, then we'd have listened to them and maybe reconsidered." [HNS6]}

From a purely practical viewpoint, there is no doubt that clotting factor switching becomes easier with experience.

\section{"It's all about the planning. You know what the others were like, so you can pre-empt or have more knowledge of how to broach the subject or talk to your patients about it, compared to if you'd not done it before." [HNS1p]}

Nevertheless, the process could be made easier for health care professionals. Asked for practical suggestions regarding how to make switching process easier for health care professionals, nurses' comments suggested a strong role for contact with and support from other nurses:

\section{"Actually having contemporaries who do it} elsewhere and knowing how it's going is helpful. Having a bit of admin support, having draft letters, having the support tear-off things to put in the letters about how to mix the product, and having a YouTube thing to direct people to, or... Having those sorts of things is really helpful." [HNS7]

However, there is a need for commissioners to recognise that the current climate of innovation may not sit easily with a target-based tender. As one nurse participant noted:

"In the current climate, with so many new
products coming onto the market and so many
trials, it's difficult to sometimes hit targets when
you've got patients out of that commissioned
work because they're on trial products." [HNS3]

"I'm finding that quite a challenge, to monitor the volumes ... If we don't get the volumes, what are the consequences? That we have to pay full price? And that's driven by NHS England and I think they need to consider that sometimes, clinically, that's not going to happen. Because the considerations are the patients are going through gene therapy, so you're not going to get the volumes on any product, and patients going through $P K$ studies and other trial patients who are on trials. It does worry me that if we don't get the volumes, that if we've got evidence to back it up, then someone at the top end should have thought about that when they put the tender out." [HNS5]

One unforeseen consequence of the tender-based system is that haemophilia nurses find themselves under increasing pressure from pharmaceutical companies 'encouraging' switches to their product.

"We did have one company putting loads of pressure on us for people to swap. 'You know, you should have swapped by now ... you should be switching because you're below your average volumes to cover the cost of what you should have got by the end of March,' and things like that. It's a bit worrying that they seem to have access to that data." [HNS1p]

Clearly, such pressure on health care professionals is unacceptable. It is the responsibility of medical and nursing educators and leaders to ensure that all centre staff involved in delivering product switches understand the commercial reasons behind such approaches. 


\section{CONCLUSION}

Switching patients' treatment from one clotting factor to another saves money for the health service but is not a cost-free exercise for treatment centres, which have no additional resources allocated for the tasks involved. It is associated with an additional workload, which falls principally to the haemophilia specialist nurse and data management teams. For the process described in this study, there was no national guidance on which patients should have their product switched, and many nurses described decision-making based on their knowledge of individual patients, either alone or, more often, as part of the multidisciplinary team.

Standardised guides to switching, including template letters, were well received and acknowledged as making the overall process easier

\section{ACKNOWLEDGEMENTS}

We thank all participants of this study, which was designed by the authors and funded by Novo Nordisk. The original practical guide to switching factor concentrates was developed by Chris Harrington.

The authors have advised no interests that might be perceived as posing a conflict or bias.

This paper reports on a survey of health care professionals and did not require research board approval. Participants responded to the survey knowing that any comments may be reported.

\section{ORCID}

Debra Pollard (iD https://orcid.org/0000-0002-7797-3500 Kate Khair (iD https://orcid.org/0000-0003-2001-5958 Mike Holland (iD) https://orcid.org/0000-0002-9173-4100

\section{REFERENCES}

1. Keeling D, Tait C, Makris M. Guideline on the selection and use of therapeutic products to treat haemophilia and other hereditary bleeding disorders. A United Kingdom Haemophilia Center Doctors' Organisation (UKHCDO) guideline approved by the British Committee for Standards in Haematology. Haemophilia 2008; 14(4): 671-84. doi: 10.1111/j.13652516.2008.01695.x

2. Department of Health. Government invests an extra $£ 88$ million in haemophilia treatments. 12 February 2003. Available at https://webarchive.nationalarchives.gov.uk/20070402232650/ http://www.dh.gov.uk/en/Publicationsandstatistics/ Pressreleases/DH_4024694 (accessed 28 April 2020).

3. Hay CR. Purchasing factor concentrates in the 21 st century through competitive tendering. Haemophilia 2013; 19(5): 660-7. doi: 10.1111/hae.12169.

4. Harrington C, Hay C, Vidler V, Dattani R, Heygate K. Switching factor products: selecting patients and managing the process. J Haem Pract 2014; 1(2): 24-29. doi: 10.17225/jhp.00021.

5. Collins $P$, Chalmers $E$, Chowdary $P$, et al. The use of enhanced half-life coagulation factor concentrates in routine clinical practice: guidance from UKHCDO. Haemophilia 2016; 22(4): 487-98. doi: 10.1111/hae.13013.

6. Khair K, Pollard D, Harrison C, Hook S, O'Driscoll M, Holland M. HOw Patients view Extended half-life products: Impressions from real-world experience (The HOPE study). Haemophilia 2019; 25(5): 814-20. doi: 10.1111/hae.13803.

7. Pollard D, Khair K, Percier C, Wong Y, Shoemark R. Evaluation of MixPro ${ }^{\circledR}$ among users and nurses. J Haem Pract 2017; 5(1): 12-23. doi: doi.org/10.17225/jhp00106

8. Santagostino E, Auerswald G, Benson G, et al. Switching treatments in haemophilia: is there a risk of inhibitor development? Eur J Haematol 2014; 94: 284-89. doi: 10.1111/ ejh.12433.

9. Hay CR, Palmer BP, Chalmers EA, et al. The incidence of factor VIII inhibitors in severe haemophilia A following a major switch from full length to B-domain-deleted factor VIII: a prospective cohort comparison. Haemophilia 2015; 21: 219-26. doi: 10.1111/hae.12563.

10. Department of Health \& Social Care. The NHS Choice Framework: what choices are available to me in the NHS? 29 April 2016. Available at https://www.gov.uk/government/publications/ the-nhs-choice-framework (accessed 28 April 2020).

HOW TO CITE THIS ARTICLE:

Pollard D, Khair K, Holland M. Switching factor products:

nurses' experience with NovoEight. J Haem Pract 2020;

7(1): 59-69. https://doi.org/10.17225/jhp00156.

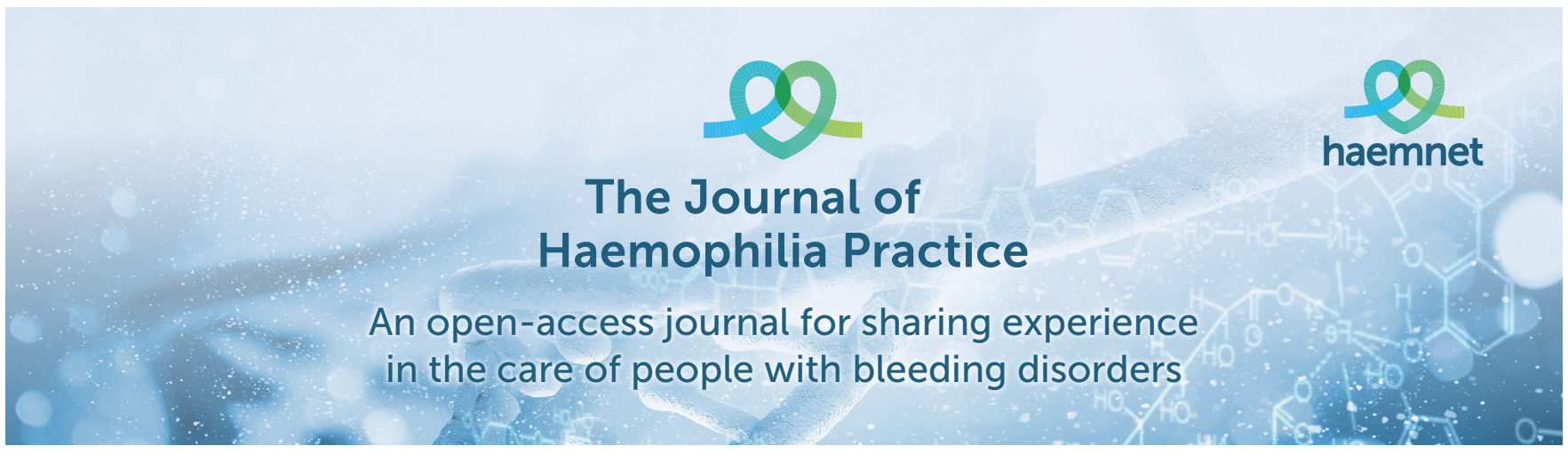


Table 1: Practical guide to switching factor concentrate post-tender

\begin{tabular}{|c|c|}
\hline TENDER OUTCOME & $\begin{array}{l}\text { PRODUCTS AND VOLUMES ESTABLISHED NATIONALLY. } \\
\text { ENSURE CENTRE AND REGIONAL ALLOCATION ARE KNOWN. } \\
\text { ESTABLISH A TIMELINE FOR ACHIEVING THE CENTRE'S ALLOCATED VOLUMES }\end{array}$ \\
\hline Staff Preparation & $\begin{array}{l}\text { Knowledge of products } \\
\text { Liaise with laboratory to ensure assay implications are assessed and safe } \\
\text { Know data requirements for selecting patients and ongoing monitoring of product use } \\
\text { Obtain supply of reconstitution device demo kits and patient product information } \\
\text { Notify home delivery companies as soon as possible that there will be product change }\end{array}$ \\
\hline \multirow[t]{4}{*}{ Communication } & $\begin{array}{l}\text { Patients/Parents } \\
\text { Discuss upcoming tender at clinic appointments and prepare for the possibility of switching } \\
\text { products } \\
\text { Explain that whilst inhibitor risk used to be a concern with product switching, the experience } \\
\text { since the first national tender in 2004, and internationally where switching is more routine, } \\
\text { has revealed no evidence of increased risk following a switch. } \\
\text { Terms such as "different brand" can be useful in explaining the difference between products. } \\
\text { Some patients will be aware that many drugs are produced by more than one pharmaceutical } \\
\text { company and have different branding. The brand is changed from time to time if the NHS can } \\
\text { get a better price. } \\
\text { Consider a letter to all patients on home treatment about the tender, raising the possibility } \\
\text { that they may be asked to switch. This can help to raise awareness that the tenders happen } \\
\text { regularly and, if not on this occasion, you may be required to switch another time. } \\
\text { A telephone consultation may be appropriate for some patients who are selected to switch. } \\
\text { This may be all that is needed if they are familiar with the reconstitution device. Discuss } \\
\text { running down stock of current product and managing transition to the new. } \\
\text { Patients/parents should be advised to finish their supply of existing product before starting the } \\
\text { new one - and not to mix brands together } \\
\text { Remind to choose the right product name when entering data onto Haemtrack } \\
\text { Centres who use Partnership Agreements - consider changing product information to } \\
\text { generic recombinant factor VIIl or IX }\end{array}$ \\
\hline & $\begin{array}{l}\text { Pharmacy/Blood Bank } \\
\text { Ensure new product entered onto their systems } \\
\text { Liaise re. adjusting stock levels }\end{array}$ \\
\hline & $\begin{array}{l}\text { Home Delivery Company } \\
\text { As soon as the Centre is aware, inform about product changes. Limit deliveries to no more } \\
\text { than } 4 \text { weeks' supply. If within their service specification with the Centre, they may be } \\
\text { requested to assist with home stock check. }\end{array}$ \\
\hline & $\begin{array}{l}\text { Key Care Personnel } \\
\text { Inform those involved in the individual's care about change of product, e.g. shared care } \\
\text { centres, local hospital, GP, residential care. } \\
\text { Ensure all staff involved in administering clotting factor concentrate know how to safely } \\
\text { and efficiently reconstitute and administer product, e.g. on-call doctors, ward or A\&E staff. } \\
\text { Educational materials should be available e.g. where products are stored, on hospital intranet, } \\
\text { given to staff at handover alongside any product. }\end{array}$ \\
\hline
\end{tabular}




\begin{tabular}{|c|c|}
\hline \multirow[t]{2}{*}{ Selecting Patients } & $\begin{array}{l}\text { Draw up list of potential patients to switch } \\
\text { Examine product use of individuals on home treatment/high users over at least a year, } \\
\text { adjusting for those who have had surgery } \\
\text { Aim to keep household members on same product } \\
\text { Include patients who are currently: } \\
\text { - High users } \\
\text { - On a product that will no longer be available e.g. Helixate } \\
\text { - On a plasma-derived product and due to switch to recombinant } \\
\text { Review list with MDT } \\
\text { Consider any reasons for reluctance to switch e.g. } \\
\text { - Pending surgery } \\
\text { - Under } 50 \text { exposure days } \\
\text { - Children and parents new to managing home treatment } \\
\text { - Likely anxiety e.g. extreme worry about treatment safety and the consequences of changing } \\
\text { treatment - often with family history of transfusion transmitted disease or inhibitors. } \\
\text { - Communication issues e.g. learning difficulties, language }\end{array}$ \\
\hline & $\begin{array}{l}\text { Agree list of propose patients } \\
\text { As an MDT decide on a consistent approach to patients who may decline switch. }\end{array}$ \\
\hline \multirow[t]{2}{*}{ Managing Stock } & $\begin{array}{l}\text { Hospital } \\
\text { Plan for transition } \\
\text { Review stock levels and revise re-order levels } \\
\text { Liaise with local network hospitals re revision of their stock holding }\end{array}$ \\
\hline & $\begin{array}{l}\text { Home Treatment } \\
\text { Stock check existing product - patient/home delivery.company - and plan to run down supply } \\
\text { Change prescriptions for home delivery }\end{array}$ \\
\hline \multirow[t]{2}{*}{ Post-Switch } & $\begin{array}{l}\text { Data } \\
\text { Review trends in individual use - Haemtrack validation } \\
\text { Review overall volumes used monthly - at } 3 \text { months consider if further patients need to } \\
\text { switch to make target volumes }\end{array}$ \\
\hline & $\begin{array}{l}\text { Clinical Monitoring } \\
\text { Encourage patients to ring Centre with concerns } \\
\text { Respond to any unexpected factor response results, reports of any adverse events } \\
\text { or perceived lack of efficacy. Report any confirmed adverse events including lack of } \\
\text { efficacy on HCIS \&/or EUHASS. } \\
\text { Inhibitor screen/PK if indicated } \\
\text { Otherwise no extra measures beyond standard clinical care are recommended by UKHCDO }\end{array}$ \\
\hline
\end{tabular}




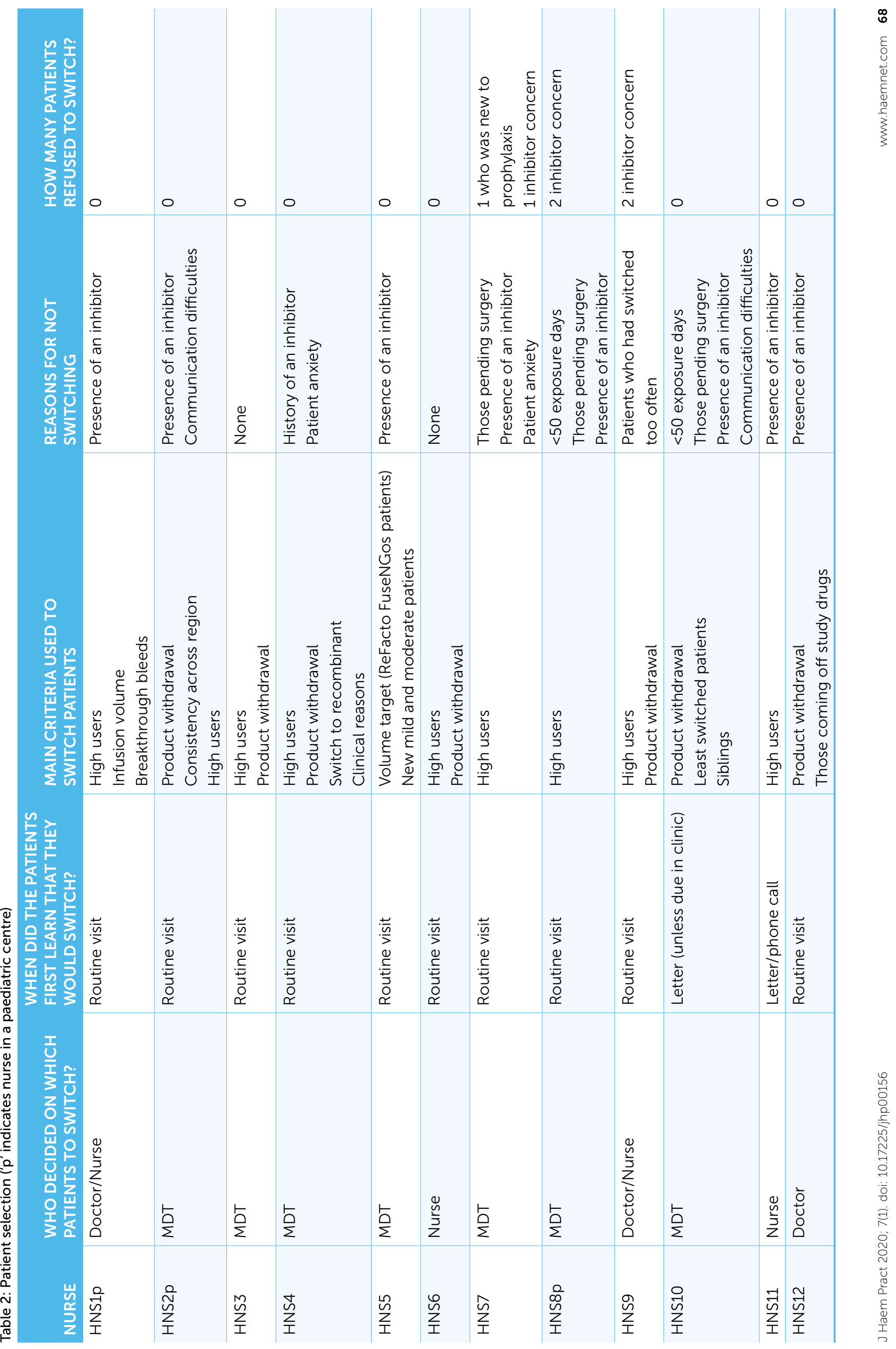




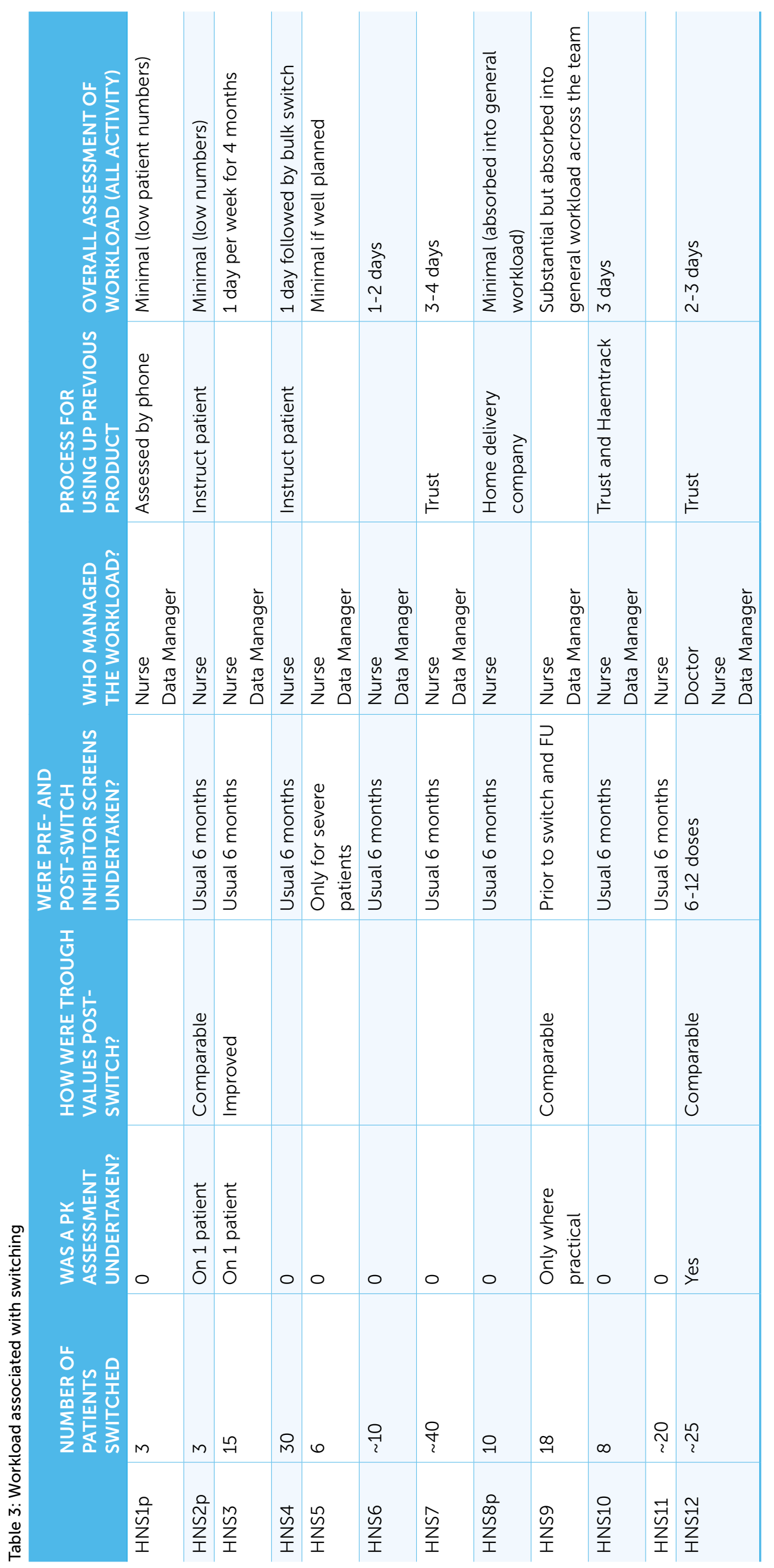

